Article

\title{
Demonstration of Transmission Mode Soft X-ray NEXAFS Using Third- and Fifth-Order Harmonics of FEL Radiation at SACLA BL1
}

\author{
Hiroshi Iwayama ${ }^{1,2,3, *(0)}$, Masanari Nagasaka ${ }^{1,2,3}{ }^{(0)}$, Ichiro Inoue ${ }^{3}$, Shigeki Owada ${ }^{3,4}$, \\ Makina Yabashi ${ }^{3,4}$ (D) and James R. Harries ${ }^{3,5}$ \\ 1 Institute for Molecular Science, Myodaiji, Okazaki 444-8585, Japan; nagasaka@ims.ac.jp \\ 2 SOKENDAI, The Graduate University for Advanced Studies, Myodaiji, Okazaki 444-8585, Japan \\ 3 RIKEN, SPring-8 Center, Sayo, Hyogo 679-5148, Japan; inoue@spring8.or.jp (I.I.); osigeki@spring8.or.jp (S.O.); \\ yabashi@spring8.or.jp (M.Y.); harries.james@qst.go.jp (J.R.H.) \\ 4 JASRI, 1-1-1, Kouto, Sayo-cho, Sayo-gun, Hyogo 679-5198, Japan \\ 5 QST, SPring-8, Kouto 1-1-1, Sayo, Hyogo 679-5148, Japan \\ * Correspondence: iwayama@ims.ac.jp; Tel.: +81-564-55-7403
}

Received: 7 October 2020; Accepted: 3 November 2020; Published: 5 November 2020

\begin{abstract}
We demonstrate the applicability of third- and fifth-order harmonics of free-electron laser (FEL) radiation for soft X-ray absorption spectroscopy in the transmission mode at SACLA BL1, which covers a photon energy range of 20 to $150 \mathrm{eV}$ in the fundamental FEL radiation. By using the third- and fifth-order harmonics of the FEL radiation, we successfully recorded near-edge X-ray absorption fine structure (NEXAFS) spectra for Ar $2 \mathrm{p}$ core ionization and $\mathrm{CO}_{2} \mathrm{C} 1 \mathrm{~s}$ and $\mathrm{O}$ 1s core ionizations. Our results show that the utilization of third- and fifth-order harmonics can significantly extend the available photon energies for NEXAFS spectroscopy using an FEL and opens the door to femtosecond pump-probe NEXAFS using a soft X-ray FEL.
\end{abstract}

Keywords: XFEL; soft X-ray absorption spectroscopy; high-order harmonics

\section{Introduction}

Free-electron lasers (FELs) [1] provide a source of intense, coherent, ultrafast, and continuously tunable radiation. In particular, since the development of the self-amplified spontaneous-emission (SASE) technique [2,3], which extended the available laser wavelengths to the X-ray regime [4-8], great interest has been shown by user communities over a wide range of fields in physics $[9,10]$, chemistry [11,12], and structural biology [13,14].

X-ray FELs have made it possible to observe structural changes which occur at femtosecond timescales. For example, femtosecond bond formation was successfully observed by obtaining an X-ray diffraction image of three $\mathrm{Au}(\mathrm{CN})_{2}{ }^{-}$molecules in solution using a $267 \mathrm{~nm}$ wavelength pump and X-ray FEL probe $[15,16]$. However, techniques using diffraction mainly require X-rays of energy $5 \mathrm{keV}$ or higher, and heavy elements such as $\mathrm{Au}$ are required as scatterers in order to obtain sufficient signal strength. It is thus difficult to apply this method to biological molecules, which consist mainly of light elements such as carbon, nitrogen, and oxygen, and do not contain heavy elements.

The recent development of high-order harmonic generation (HHG) technology using lasers operating at wavelengths of $1 \mu \mathrm{m}$ or longer has led to the availability of ultrashort pulsed light in the soft X-ray region [17]. The soft X-ray region of 200 to $1000 \mathrm{eV}$ includes the K-shell absorption edges of light elements such as carbon $(280 \mathrm{eV})$, nitrogen $(400 \mathrm{eV})$, and oxygen $(530 \mathrm{eV})$ and the L-shell absorption edges of transition metals such as chromium (580 eV), iron (720 eV), and cobalt $(790 \mathrm{eV})$. Near edge X-ray absorption fine structure (NEXAFS) [18], a workhorse technique using 
non-time-resolved synchrotron radiation, is sensitive to the local chemical environment of the specific atom targeted. By analyzing NEXAFS spectra, one can acquire information on the local structure, electronic, and spin state. Time-resolved NEXAFS in the soft X-ray region, especially above the carbon K-edge energy, is a promising tool and would enable the investigation of ultrafast structural, electron, and spin dynamics. Femtosecond time-resolved soft X-ray absorption spectroscopy by this HHG technology has been performed, and the photodissociation processes of $\mathrm{CF}_{4}$ [19] and $\mathrm{NO}$ [20] molecules were observed. However, at present, usable light intensity can only be obtained for energies of up to about $400 \mathrm{eV}$ (nitrogen absorption edge) [21]. Currently, the development of time-resolved soft X-ray absorption spectroscopy in the 500 to $1000 \mathrm{eV}$ region is insufficient.

In 2020, at the XFEL facility LCLS in the United States, using soft X-ray absorption spectroscopy around the oxygen $\mathrm{K}$-edge energy, it became clear that the generation of $\mathrm{OH}$ radicals by the chemical reaction of $\mathrm{H}_{2} \mathrm{O}^{+}$ions $\left(\mathrm{H}_{2} \mathrm{O}^{+}+\mathrm{H}_{2} \mathrm{O} \alpha \rightarrow \mathrm{OH}+\mathrm{H}_{3} \mathrm{O}^{+}\right)$was about 46 femtoseconds [22], which attracted great interest from all over the world. Above $500 \mathrm{eV}$, the ultra-short pulses offered by an FEL are ideal for this application.

The SACLA BL1 FEL [23], targets the extreme ultraviolet (EUV) wavelength regime, providing photon energies ranging from 20 to $150 \mathrm{eV}$ in the fundamental FEL radiation. Many successful applications have been made-for example, in EUV nonlinear optics [24,25] and ultrafast time-resolved spectroscopy [26].

In this paper, we propose and demonstrate the utilization of third- and fifth-order harmonics in FEL radiation to extend the available photon energy region. While the highest available photon energy is $150 \mathrm{eV}$ in the fundamental FEL radiation at SACLA BL1, we demonstrate soft X-ray absorption spectroscopy at the $\mathrm{Ar} 2 \mathrm{p}$ and $\mathrm{CO}_{2} \mathrm{C} 1 \mathrm{~s}$ and $\mathrm{O} 1$ s edges, successfully recording NEXAFS spectra by using the third- and fifth-order harmonics in the FEL radiation.

\section{Methods}

The experiments were carried out at SACLA BL1, which covers a photon energy range of 20 to $150 \mathrm{eV}$ in the fundamental FEL radiation. The FEL radiation was linearly polarized in the horizontal direction, and the repetition rate was $60 \mathrm{~Hz}$. A schematic diagram of the experimental setup for soft $\mathrm{X}$-ray absorption spectroscopy in transmission mode with a gas cell is presented in Figure 1. The FEL pulses are transported and focused with a carbon-coated Kirkpatrick-Baez (KB) focusing mirror system [23]. The focus size was about $10 \mu \mathrm{m}$ in diameter. The photon energy cutoff for the $\mathrm{KB}$ mirror system at an incident angle of $1.5^{\circ}$ is roughly $1 \mathrm{keV}$, allowing soft $\mathrm{X}$-ray absorption spectroscopy using the third- and fifth-order harmonics. In these experiments, we used photon energies of 82,98 , and $108 \mathrm{eV}$ as the fundamental FEL radiation. In this energy region, pulse energies are roughly $100 \mu \mathrm{J}$ [23]. At a photon energy of $100 \mathrm{eV}$, the pulse energy of the third harmonic is estimated to be $0.3 \%$ [23] of the fundamental FEL radiation (i.e., around $300 \mathrm{~nJ}$ ). According to the previous theoretical work [27], we estimate the pulse energy of the fifth-order harmonic to be around $0.01 \%$ of the fundamental FEL radiation $(10 \mathrm{~nJ})$. Full details of the beamline are described in [23]. Aluminum filters of thicknesses $0.5,0.4$, and $1.4 \mu \mathrm{m}$ were used to selectively absorb the fundamental FEL radiation and optimize signal-to-background ratios of the $\mathrm{Ar} 2 \mathrm{p}, \mathrm{CO}_{2} \mathrm{C}$ 1s, and $\mathrm{CO}_{2} \mathrm{O}$ 1s NEXAFS spectra, respectively. For example, the $0.5-\mu \mathrm{m}$-thick filter provides transmissions of $0.14 \times 10^{-5}$ at $86 \mathrm{eV}$ (fundamental) and $0.4 \times 10^{-2}$ at $246 \mathrm{eV}$ (third order).

The gas cell confines sample gas between two 100-nm-thick $\mathrm{Si}_{3} \mathrm{~N}_{4}$ membrane windows, and for the experiments described here we used an absorption length of $10 \mathrm{~mm}$. To avoid nonlinear optical effects, the gas cell was positioned $400 \mathrm{~mm}$ upstream of the FEL focus point. The FEL beam size was estimated to be about $1.4 \mathrm{~mm}$ in diameter at the gas cell position. The sample gas pressures for the $\mathrm{Ar} 2 \mathrm{p}$, $\mathrm{CO}_{2} \mathrm{C}$ 1s, and $\mathrm{CO}_{2} \mathrm{O} 1 \mathrm{~s}$ NEXAFS measurements were 720,350 , and $580 \mathrm{~Pa}$, respectively.

Spectra of radiation transmitted through the gas cell were recorded using a flat-field imaging grazing incidence spectrometer (XUV639, manufactured by Shinkukogaku Co. Ltd., Tokyo, Japan), which was set on the same axis as the incident FEL axis. The FEL pulse was dispersed by an 
aberration-corrected concave grating with a groove density of 600 lines $/ \mathrm{mm}$ and focused on the detection plane of a thermoelectrically-cooled CCD camera (DO420-BN, Andor Technolgy Ltd). Assuming that 1 electron-hole pair can be made per $3.6 \mathrm{eV}$ [28,29], the CCD intensity was converted to the number of photons detected. Error bars in absorption spectra were estimated from statistical errors of the number of photons detected.

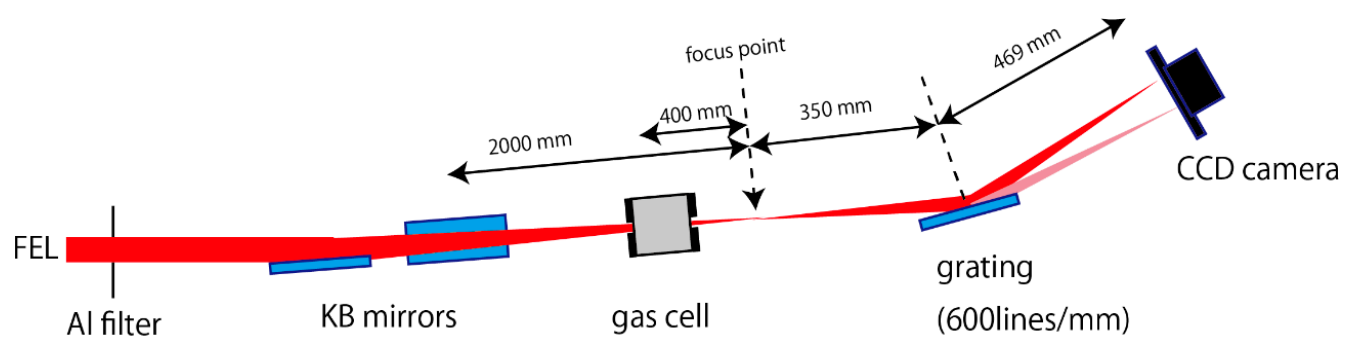

Figure 1. Schematic drawing of the experimental setup for soft $X$-ray absorption spectroscopy in transmission mode at SACLA BL1.

\section{Results}

NEXAFS spectra can be generated from our transmission mode spectra using the Lambert-Beer law, $\ln \left(\mathrm{I}_{0} / \mathrm{I}\right)$, where $\mathrm{I}$ and $\mathrm{I}_{0}$ are the transmission spectra recorded with and without sample gas, respectively. Figure 2a shows three typical FEL pulse spectra $\left(\mathrm{I}_{0}\right)$ recorded at BL1. The photon energy distributions have spike structures, and are different for each shot. These instable spectra may be attributed to the SASE-FEL which starts from shot noise in the electron beam. These spike structures are also observed for third- and fifth-order harmonics in the FEL radiation. In Figure 2b, the evolution of the spectrum as a function of averaging is shown. For 100 shots or less, the spike structure remains, but it can be seen that sufficient averaging is provided by averaging over 500 shots or more. Figure $2 \mathrm{c}$ shows 1000-shot average spectra. The bottom three spectra were measured at 3 min intervals, and the upper spectrum was recorded $66 \mathrm{~min}$ after the " $0 \mathrm{~min}$ " spectrum. Since a thicker aluminum filter was used to record these spectra, it has been scaled to facilitate comparison. While the photon energy distributions are different for each shot, the average spectra are very similar and have a high reproducibility. There was little change in central light energy and width, even at $1 \mathrm{~h}$ apart. With the current experimental setup, we are unable to record both I and $\mathrm{I}_{0}$ shot-by-shot, and here we could only compare multiple-shot average $\mathrm{I}$ and $\mathrm{I}_{0}$ recorded consecutively. For soft $\mathrm{X}$-ray absorption spectra of $\mathrm{Ar}$ and $\mathrm{CO}_{2}$ gas shown below, we averaged 3000 shots for each spectrum.
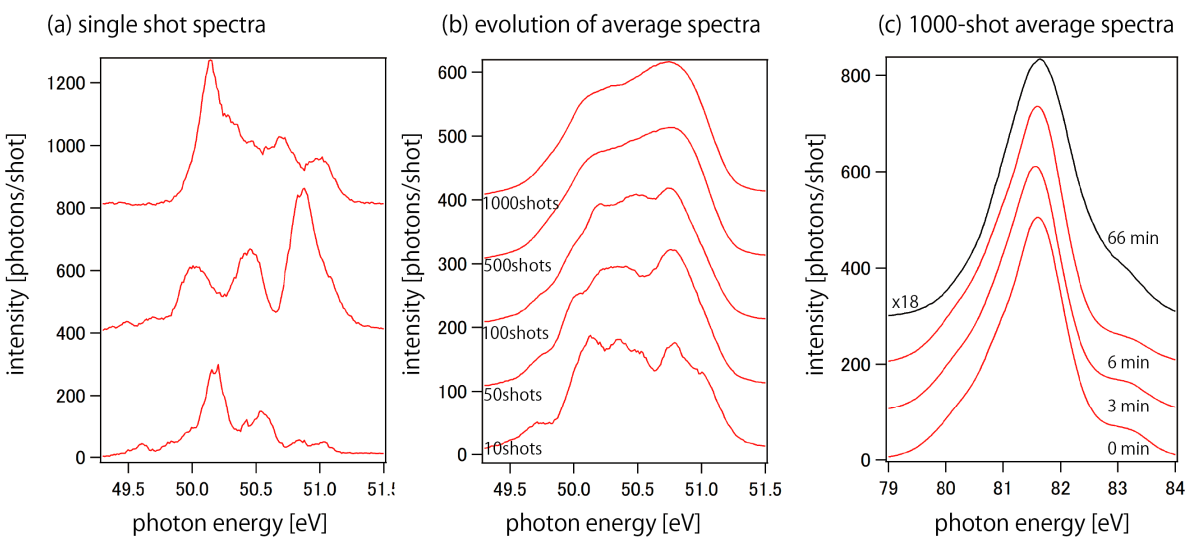

Figure 2. Typical (a) single-shot spectra, (b) the evolution of the spectrum as a function of the number of averaging, and (c) 1000-shot average spectra of incident free-electron laser (FEL) pulses.

Figure 3a shows average incident $\left(\mathrm{I}_{0}\right)$ and transmitted (I) spectra for Ar, recorded near the $2 \mathrm{p}$ edge. The photon energy of the FEL pulse was set to $82 \mathrm{eV}$, giving a third-order energy of $246 \mathrm{eV}$. 
While the intensity of the third-order harmonics is only around $0.3 \%$ [23] of the fundamental FEL radiation, the transmission geometry allows us to directly record the transmitted FEL pulses. For the transmitted spectrum I, several sharp dips can be seen. These correspond to core excitations of Ar $2 p$ $\rightarrow \mathrm{nl}$ Rydberg states. Using the Lambert-Beer law, we can obtain the transmission mode absorption spectrum from $\ln \left(\mathrm{I}_{0} / \mathrm{I}\right)$, which is shown in Figure $3 b$. The sharp peaks correspond to Ar $2 p \rightarrow n l$ core excitations, and the overall structure of the absorption spectrum is very similar to that reported in the previous work [30]. The observed peak width of $2 \mathrm{p}_{3 / 2} \rightarrow 4 \mathrm{~s}$ at $244.4 \mathrm{eV}$ is $200 \mathrm{meV}$, whereas the natural width is $116 \mathrm{meV}$ [30]. We can thus estimate the resolution $\mathrm{E} / \Delta \mathrm{E}$ of our spectrometer to be around 1200. The spectral width of the FEL pulses is around $3 \%(\Delta \mathrm{E} / \mathrm{E})$, corresponding to $8 \mathrm{eV}$ at a photon energy of $246 \mathrm{eV}$. This energy width allows us to record a NEXAFS spectrum without changing the FEL conditions or scanning the photon energy.

We also recorded the carbon and oxygen K-edge NEXAFS spectra of $\mathrm{CO}_{2}$ molecules using the same technique. For the $\mathrm{C} 1 \mathrm{~s}$ spectra, we set the FEL pulse energy to $98 \mathrm{eV}$, and used the third order $(294 \mathrm{eV})$. For the $\mathrm{O} 1 \mathrm{~s}$ spectra, we used $108 \mathrm{eV}$ and the fifth order $(540 \mathrm{eV})$. Figure 4 show the resulting $\mathrm{C}$ 1s and O 1s NEXAFS spectra. The strong peaks at photon energies of 291 and $533 \mathrm{eV}$ are due to carbon and oxygen $1 \mathrm{~s} \rightarrow \pi^{*}$ core excitations. The spectra also show $\mathrm{C} 1 \mathrm{~s} \rightarrow 3 \mathrm{~s}$ Rydberg and $\mathrm{O} 1 \mathrm{~s} \rightarrow$ $\sigma^{*}$ core excitations. Due to the lower cross-sections and the lower photon intensity, the spectra are of lower quality than that recorded for Ar 2p. Both the $\mathrm{CO}_{2} \mathrm{C}$ 1s and the $\mathrm{CO}_{2} \mathrm{O}$ 1s spectra are similar to previous work $[18,31]$. The signal-to-noise ratio for $\mathrm{CO}_{2} \mathrm{C}$ 1s and the $\mathrm{CO}_{2} \mathrm{O} 1 \mathrm{~s}$ spectra could be improved to match the Ar 2p spectrum by increasing the number of spectra used on average by a factor of 10. The 7th order of FEL pulses centered at $76 \mathrm{eV}$ were too weak to be used to record O K-edge NEXAFS spectra.
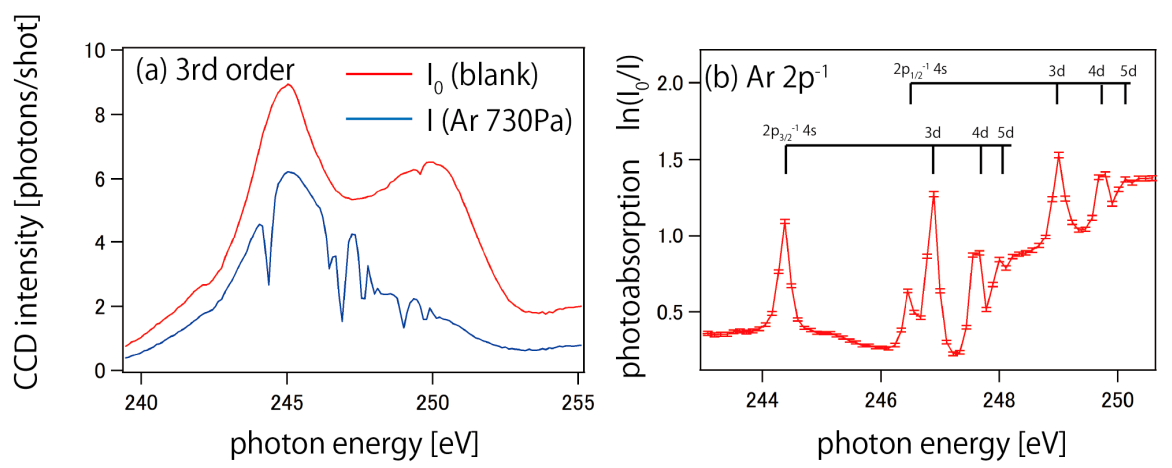

Figure 3. (a) Incident $\left(\mathrm{I}_{0}\right)$ and transmitted (I) 3000-shot average spectra for Ar gas. The photon energy of the incident FEL pulses was $82 \mathrm{eV}$ in the fundamental FEL radiation. (b) Absorption spectrum for Ar gas obtained from $\ln \left(\mathrm{I}_{0} / \mathrm{I}\right)$.
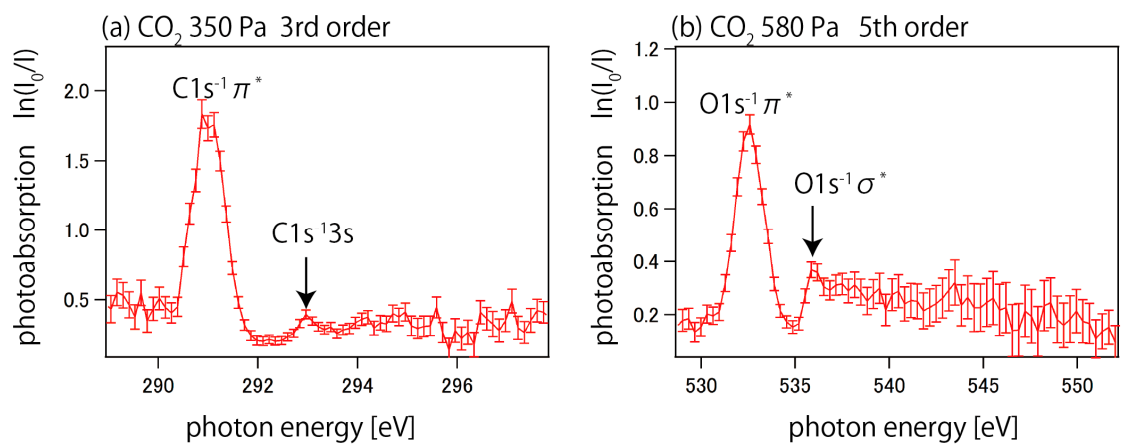

Figure 4. Soft $\mathrm{X}$-ray absorption spectra for $\mathrm{CO}_{2}$ gas around the (a) $\mathrm{C} 1$ s and (b) $\mathrm{O}$ 1s core ionization Table 98 and 108 eV, respectively. 


\section{Summary}

We proposed and demonstrated the utilization of the third- and fifth-order harmonics in FEL radiation for soft $\mathrm{X}$-ray absorption spectroscopy in transmission mode. We successfully recorded Ar 2p, $\mathrm{CO}_{2} \mathrm{C} 1 \mathrm{~s}$, and $\mathrm{CO}_{2} \mathrm{O} 1 \mathrm{~s}$ NEXAFS spectra using the third- and fifth-order harmonics of the FEL radiation. The use of fifth-order harmonics extends the upper range of available photon energies at SACLA BL1 from 150 to $750 \mathrm{eV}$, covering the K-edge energies of light elements such as carbon, oxygen, and nitrogen, and the L-edge energies of transition metals. Since, especially at $500 \mathrm{eV}$ and above, HHG technology does not currently provide sufficient light intensity, soft X-ray FELs are the only available light source for soft X-ray absorption spectroscopy around the oxygen K-edge energy. By combining with a synchronized visible or infrared laser, pump-probe experiments will enable time-resolved soft X-ray absorption spectroscopy at SACLA BL1.

Author Contributions: H.I., M.N. and J.R.H. designed the experimental platform and performed experiments. H.I. analyzed the data. H.I. and J.R.H. wrote the paper. I.I., S.O. and M.Y. calibrated and controlled the beamline of SACLA BL1. All authors have read and agreed to the published version of the manuscript.

Funding: This research received no external funding.

Acknowledgments: The experiments were performed at SACLA BL1 with support of SACLA Basic Development Program. The authors would like to acknowledge the supporting members of the SACLA facility.

Conflicts of Interest: The authors declare no conflict of interest.

\section{References}

1. Madey, J. Stimulated emission of bremsstrahlung in a periodic magnetic field. J. Appl. Phys. 1971, 42, 1906-1913. [CrossRef]

2. Kondratenko, A.M.; Saldin, E.L. Generation of coherent radiation by a relativistic electron beam in an ondulator. Part. Accel. 1980, 10, 207-216.

3. Bonifacio, R.; Pellegrini, C.; Narducci, L.M. Collective instabilities and high-gain regime in a free electron laser. Opt. Commun. 1984, 50, 373-378. [CrossRef]

4. Emma, P.; Akre, R.; Arthur, J.; Bionta, R.; Bostedt, C.; Bozek, J.; Brachmann, A.; Bucksbaum, P.; Coee, R.; Decker, F.-J.; et al. First lasing and operation of an ångstrom-wavelength free-electron laser. Nat. Photonics 2010, 4, 641-647. [CrossRef]

5. Ishikawa, T.; Aoyagi, H.; Asaka, T.; Asano, Y.; Azumi, N.; Bizen, T.; Ego, H.; Fukami, K.; Fukui, T.; Furukawa, Y.; et al. A compact X-ray free-electron laser emitting in the sub-ångström region. Nat. Photonics 2012, 6, 540-544. [CrossRef]

6. Kang, H.S.; Min, C.-K.; Heo, H.; Kim, C.; Yang, H.; Kim, G.; Nam, I.; Baek, S.Y.; Choi, H.-J.; Mun, G.; et al. Hard X-ray free-electron laser with femtosecond-scale timing jitter. Nat. Photonics 2017, 11, 708-713. [CrossRef]

7. Tschentscher, T.; Bressler, C.; Grünert, J.; Madsen, A.; Mancuso, A.P.; Meyer, M.; Scherz, A.; Sinn, H.; Zastrau, U. Photon Beam Transport and Scientific Instruments at the European XFEL. Appl. Sci. 2017, 7, 592. [CrossRef]

8. Milne, C.; Schietinger, T.; Aiba, M.; Alarcon, A.; Alex, J.; Anghel, A.; Arsov, V.; Beard, C.; Beaud, P.; Bettoni, S.; et al. SwissFEL: The Swiss X-ray Free Electron Laser. Appl. Sci. 2017, 7, 720. [CrossRef]

9. Rohringer, N.; Ryan, D.; London, R.A.; Purvis, M.; Albert, F.; Dunn, J.; Bozek, J.D.; Bostedt, C.; Graf, A.; Hill, R.; et al. Atomic inner-shell X-ray laser at 1.46 nanometres pumped by an X-ray free-electron laser. Nature 2012, 481, 488-491. [CrossRef] [PubMed]

10. Tamasaku, K.; Shigemasa, E.; Inubushi, Y.; Katayama, T.; Sawada, K.; Yumoto, H.; Ohashi, H.; Yabashi, M.; Yamaguchi, K.; Ishikawa, T. X-ray two-photon absorption competing against single and sequential multiphoton processes. Nat. Photonics 2014, 8, 313-316. [CrossRef]

11. Wernet, P.; Kunnus, K.; Josefsson, I.; Rajkovic, I.; Quevedo, W.; Beye, M.; Schreck, S.; Grübel, S.; Scholz, M.; Nordlund, D.; et al. Orbital-specific mapping of the ligand exchange dynamics of $\mathrm{Fe}(\mathrm{CO})_{5}$ in solution. Nature 2015, 520, 78-81. [CrossRef] 
12. Erk, B.; Boll, R.; Trippel, S.; Anielski, D.; Foucar, L.; Rudek, B.; Epp, S.W.; Coffee, R.; Carron, S.; Schorb, S.; et al. Imaging charge transfer in iodomethane upon x-ray photoabsorption. Science 2014, 345, 288-291. [CrossRef] [PubMed]

13. Boutet, S.; Lomb, L.; Williams, G.J.; Barends, T.R.M.; Aquila, A.; Doak, R.B.; Weierstall, U.; DePonte, D.P.; Steinbrener, J.; Shoeman, R.L.; et al. High resolution protein structure determination by serial femtosecond crystallography. Science 2012, 337, 362-364. [CrossRef] [PubMed]

14. Suga, M.; Akita, F.; Hirata, K.; Ueno, G.; Murakami, H.; Nakajima, Y.; Shimizu, T.; Yamashita, K.; Yamamoto, M.; Ago, H.; et al. Native structure of photosystem II at $1.95 \AA$ A resolution viewed by femtosecond X-ray pulses. Nature 2014, 517, 99-103. [CrossRef]

15. Kim, K.H.; Kim, J.G.; Nozawa, S.; Sato, T.; Oang, K.Y.; Kim, T.W.; Ki, H.; Jo, J.; Park, S.; Song, C.; et al. Direct observation of bond formation in solution with femtosecond X-ray scattering. Nature 2015, 518, 385. [CrossRef]

16. Kim, J.G.; Nozawa, S.; Kim, H.; Choi, E.H.; Sato, T.; Kim, T.W.; Kim, K.H.; Ki, H.; Kim, J.; Choi, M.; et al. Mapping the emergence of molecular vibrations mediating bond formation. Nature 2020, 582, 520. [CrossRef]

17. Popmintchev, T.; Chen, M.C.; Popmintchev, D.; Arpin, P.; Brown, S.; Ališauskas, S.; Andriukaitis, G.; Balčiunas, T.; Mücke, O.D.; Pugzlys, A.; et al. Bright coherent ultrahigh harmonics in the keV X-ray regime from mid-infrared femtosecond lasers. Science 2012, 336, 1287. [CrossRef]

18. Stöhr, J. NEXAFS Spectroscopy; Springer: Berlin, Germany, 1992.

19. Pertot, Y.; Schmidt, C.; Mattews, M.; Chauvet, A.; Huppert, M.; Svoboda, V.; Conta, A.V.; Tehlar, A.; Baykusheva, D.; Wolf, J.P.; et al. Time-resolved x-ray absorption spectroscopy with a water window high-harmonic source. Science 2017, 355, 264. [CrossRef] [PubMed]

20. Saito, N.; Sannohe, H.; Ishii, N.; Kanai, T.; Kosugi, N.; Wu, Y.; Chew, A.; Han, S.; Chang, Z.; Itatani, J. Real-time observation of electronic, vibrational, and rotational dynamics in nitric oxide with nitric oxide with attosecond soft x-ray pulses at $400 \mathrm{eV}$. Optica 2019, 6, 1542. [CrossRef]

21. Kraus, P.M.; Zürch, M.; Cushing, S.K.; Neumark, D.M.; Leone, S.R. The ultrafast X-ray spectroscopic revolution in chemical dynamics. Nat. Rev. Chem. 2018, 2, 82-94. [CrossRef]

22. Loh, Z.H.; Doumy, G.; Arnold, C.; Kjellsson, L.; Southworth, S.H.; Haddad, A.A.; Kumagai, Y.; Tu, M.F.; Ho, P.J.; March, A.M.; et al. Observation of the fastest chemical processes in the radiolysis of water. Science 2020, 367, 179. [PubMed]

23. Owada, S.; Togawa, K.; Inagaki, T.; Hara, T.; Tanaka, T.; Joti, Y.; Koyama, T.; Nakajima, K.; Ohashi, H.; Senba, Y.; et al. A soft X-ray free-electron laser beamline at SACLA: The light source, photon beamline and experimental station. J. Synchrotron Rad. 2018, 25, 282-288. [CrossRef]

24. Harries, J.R.; Iwayama, H.; Kuma, S.; Iizawa, M.; Suzuki, N.; Azuma, Y.; Inoue, I.; Owada, S.; Togashi, T.; Tono, K.; et al. Superfluorescence, free-induction decay, and four-wave mixing: Propagation of free-electron laser pulses through a dense sample of helium ions. Phys. Rev. Lett. 2018, 121, 263201. [CrossRef]

25. Fushitani, M.; Sasaki, Y.; Fujise, H.; Kawabe, Y.; Hashigaya, K.; Owada, S.; Togashi, T.; Nakajima, K.; Yabashi, M.; Hikosaka, Y.; et al. Multielectron-ion coincidence spectroscopy of Xe in extreme ultraviolet laser fields: Nonlinear multiple ionization via double core-hole states. Phys. Rev. Lett. 2020, 124, 193201. [CrossRef] [PubMed]

26. Yamamoto, K.; Moussaoui, S.E.; Hirata, Y.; Yamamoto, S.; Kubota, Y.; Owada, S.; Yabashi, M.; Seki, T.; Takanashi, K.; Matsuda, I.; et al. Element-selectively tracking ultrafast demagnetization process in Co/Pt multilayer thin films by the resonant magneto-optical Kerr effect. App. Phys. Lett. 2020, 116, 172406. [CrossRef]

27. Saldin, E.L.; Schneidmiller, E.A.; Yurkov, M.V. Properties of the third harmonics of the radiation from self-amplified spontaneous emission free electron laser. Phys. Rev. Spec. Top.-Accel. Beams 2006, 9, 030702. [CrossRef]

28. Detection Sections of the Andor CCD Camera. Available online: https://andor.oxinst.com/learning/view/ article/direct-detection (accessed on 5 November 2020).

29. Gullikson, E.M.; Korde, R.; Canfield, L.R.; Vest, R.E. Stable silicon photodiodes for absolute intensity measurements in the VUV and soft x-ray regions. J. Electron Spectrosc. Relat. Phenom. 1996, 80, 313. [CrossRef] 
30. Sairanen, O.-P.; Kivimäki, A.; Nõmmiste, E.; Aksela, H.; Aksela, S. High-resolution pre-edge structure in the inner-shell ionization threshold region of rare gases Xe, Kr, and Ar. Phys. Rev. A 1996, 54, 2834-2839. [CrossRef]

31. Adachi, J.; Kosugi, N.; Shigemasa, E.; Yagishita, A. Vibronic couplings in the C $1 \mathrm{~s} \rightarrow$ ns $\sigma_{\mathrm{g}}$ Rydberg excited states of $\mathrm{CO}_{2}$. J. Phys. Chem. 1996, 100, 19783-19788. [CrossRef]

Publisher's Note: MDPI stays neutral with regard to jurisdictional claims in published maps and institutional affiliations.

(C) 2020 by the authors. Licensee MDPI, Basel, Switzerland. This article is an open access article distributed under the terms and conditions of the Creative Commons Attribution (CC BY) license (http://creativecommons.org/licenses/by/4.0/). 